\title{
PREVISÃO DE DEMANDA: SIMULAÇÃO EM UMA EMPRESA DO SEGMENTO DE ARTIGOS PARA DANÇA, FITNESS, NATAÇÃO E SPORTSWEAR
}

\section{DEMAND FORECAST: SIMULATION IN A COMPANY OF THE SEGMENT OF ARTICLES FOR DANCE, FITNESS, SWIMMING AND SPORTSWEAR}

\author{
Tamires Mazaro Candeias*E-mail: tamires candeias@hotmail.com \\ Andréia de Menezes Olivo*E-mail: andreiaolivo@unoeste.br \\ Felipe Kesrouani Lemos* E-mail: felipeklemos@unoeste.br \\ *Universidade do Oeste Paulista(UNOESTE), Presidente Prudente, SP
}

\begin{abstract}
Resumo: A indústria de moda esportiva demonstra ser um mercado promissor com um grande potencial de crescimento. Neste sentido, este trabalho tem como objetivo identificar o método de previsão de demanda mais adequado as famílias de produtos de uma empresa do segmento de artigos para dança, fitness, natação e sportswear. O estudo considerou a Média Simples, Média Móvel, Suavização Exponencial, Suavização Exponencial com Tendência - Método de Holt e Suavização Exponencial com Tendência e Sazonalidade - Método de Holt-Winters, para simulação da previsão de demanda, por meio de planilhas eletrônicas com auxílio de codificação em linguagem VBA. Os resultados mostram que as previsões apresentaram o menor erro absoluto percentual médio (MAPE) por meio da simulação em Suavização Exponencial com Tendência e Sazonalidade - Método de HoltWinters, devido sua maior sensibilidade as características da demanda, sendo o segundo melhor método observado na maioria das famílias de produtos a Suavização Exponencial com Tendência Método de Holt e a Média Simples o método que apresentou os piores índices de previsão, com grande percentual de erro.
\end{abstract}

Palavras-chave: Previsão de Demanda. Métodos Quantitativos. Planejamento, Programação e Controle da Produção.

\begin{abstract}
The sportswear industry proves to be a promising market with great potential for growth. In this sense, this work has as its theme the most appropriate demand forecasting process as the product families of a company in the segment of articles for dance, fitness, swimming and sportswear.

The study considered the Simple Average, Moving Average, Exponential Smoothing, Exponential Smoothing with Trend - Method of Holt and Exponential Smoothing with Trend and Seasonality - Holt Winters Method, for the simulation of demand forecast, through spread sheets of Microsoft Excel with the help of macro in VBA. The results show that the forecasts presented the lowest absolute percentage error (MAPE) through simulation in Exponential Smoothing with Trend and Seasonality - Holt Winters Method due to its greater sensitivity to demand characteristics, the second the best method observed in most product families was the Smoothing with Trend - Method of Holt and the Simple Average the method that presented the worst prediction indexes, with a high percentage of error
\end{abstract}

Keywords: Demand Forescast. Quantitative Methods. Production Planning, Programming and Control.

\section{INTRODUÇÃO}

As grandes mudanças ocorridas na indústria e no mercado desafiam as 
organizações a encontrarem meios para atingirem melhor eficiência. Um dos meios utilizados, atualmente, refere-se às ferramentas que auxiliam a antever as nuances das vendas, permitindo a realização de uma previsão de demanda. A previsão de demanda de produtos e serviços é particularmente importante, por ser a base sobre a qual todos os planos da empresa são construídos, por meio dela, são fornecidas as informações básicas para o planejamento e controle das áreas funcionais, como a área de finanças e contabilidade, engenharia e pesquisa, produção, distribuição e logística, recursos humanos, marketing e vendas (LEMOS, 2006).

Dessa forma, a previsão de demanda, tema da seguinte pesquisa, auxilia no planejamento e desenvolvimento das estratégias da organização, na identificação das prioridades, nas decisões de alocação de recursos e de expansões da capacidade, no planejamento da quantidade de produtos que deverão ser desenvolvidos ou adquiridos com os fornecedores e na diminuição de perdas de vendas e estoque, sendo, portanto requisito essencial para a estabilidade dos negócios (DE SOUZA, 2012).

O estudo visa contribuir por meio da aplicação prática de um dos conceitos importantes abordados na engenharia de produção, a previsão de demanda, auxiliando no conhecimento sobre os métodos de previsão de demanda quantitativos existentes, no processo de aplicação dos métodos e na definição dos mais indicados ao negócio, com o propósito de auxiliar no planejamento e nas projeções da demanda das organizações e especificamente da empresa estudada na pesquisa, que busca a identificação da quantidade de demanda futura, a fim de planejar a produção e otimizar os processos.

De acordo com Moreira (2013), é possível classificar os métodos que proporcionam a estimação futura das vendas por diferentes critérios, mas a classificação mais simples e utilizada leva em consideração o tipo de abordagem, isso é, os conceitos e instrumentos que formam a base da previsão, por esse critério as técnicas podem ser qualitativa ou quantitativa (matemática) dependendo da disponibilidade de dados, tempo, recursos e horizonte de tempo utilizado.

Com isso, a presente pesquisa tem como objetivo, a identificação de um método quantitativo de previsão adequado às características de vendas de uma organização do segmento de artigos para dança, fitness, natação e sportswear, já que 
a mesma, ainda não utiliza um modelo de previsão para sua demanda futura, dificultando o planejamento, programação e controle de todas as áreas funcionais e a obtenção de índices apropriados de capacidade, recursos financeiros e de estrutura em geral para suprir as vendas futuras.

Para isso, foram testadas técnicas de previsão de demanda quantitativas, mais especificamente os métodos de série temporal, sendo eles a Média Simples, Média Móvel, Suavização Exponencial, Suavização Exponencial com Tendência - Método de Holt e Suavização Exponencial com Tendência e Sazonalidade - Método de HoltWinters, por meio de planilhas eletrônicas com auxílio de codificação em linguagem VBA. Em cada família de produtos foram testados os métodos citados, obtendo-se uma previsão mensal para 12 meses e calculado o erro absoluto percentual médio (MAPE) de cada uma das previsões obtidas, a fim de descobrir qual o método mais preciso.

Dessa forma, a seção 2 apresenta o crescimento da área esportiva no Brasil e a importância da previsão de vendas, bem como expõe os diferentes padrões e comportamentos de demanda, auxilia na compreensão de como são realizadas as projeções das vendas futuras e retrata as fórmulas matemáticas de cada método quantitativo de previsão de demanda aplicado na seguinte pesquisa e o cálculo de erro utilizado. A seção 3 descreve a metodologia utilizada para o desenvolvimento do trabalho, enquanto que a seção 4 mostra os resultados da aplicação dos métodos quantitativos em cada família de produtos da organização em estudo e por fim, no item 5, são apresentadas as conclusões, abordando as considerações mais relevantes obtidas.

\section{DEMANDA DO SEGMENTO ESPORTIVO}

A atual preocupação em obter qualidade de vida através da prática esportiva, sem esquecer em acompanhar a moda, vem estimulando cada vez mais a produção do segmento de vestuário esportivo e provocando um crescente avanço nos processos de fabricação desses artigos. As roupas usadas por atletas profissionais ou pessoas comuns praticantes de atividades físicas, vêm sendo desenvolvidas através de pesquisas e grandes investimentos por parte de empresas que visam 
principalmente bem-estar, comodidade, conforto e um design que agrade seus consumidores (DA CUNHA, 2011).

De acordo com a Associação Brasileira de Academias (ACAD, 2017), a indústria de moda esportiva demonstra ser um mercado promissor com um grande potencial de crescimento, segundo a pesquisa realizada pela International Health, Racquet \& Sportsclub Association (IHRSA) o Brasil ocupa o segundo lugar no ranking mundial em números de academias, ficando atrás apenas dos Estados Unidos. Existem mais de 30 mil academias em todo o Brasil e mais de nove milhões de alunos, movimentando cerca de US\$2,1 bilhões, sendo que esse segmento de academias de ginástica e condicionamento físico cresce constantemente passando por um período de alta contínua há anos, com um aumento no número de academias de 31 mil em 2015 para mais de 34 mil em 2016.

Segundo Associação Brasileira da Indústria do Esporte (ABRIESP), o Brasil possui mais de sete mil lojas especializadas no setor esportivo e outras 14 mil que vendem algum item do tipo, resultando em um faturamento anual do varejo no segmento de $R \$ 4,73$ bilhões. (SEBRAE, 2014). Dessa forma, para suprir essa demanda crescente observada no setor de moda esportiva, é essencial que as organizações realizem estudos capazes de prever suas vendas futuras, com o objetivo de possuir capacidade produtiva para atender seus consumidores satisfatoriamente.

\subsection{Previsão de Demanda}

Para Paranhos Filho (2012), as previsões são avaliações de eventos futuros incertos, com o objetivo de obter informações para o direcionamento das atividades da empresa, permitindo o planejamento da matéria prima, pessoal, capital, estoque e inúmeras outras variáveis. Segundo Chase, Jacobs e Aquilano (2006), existem duas fontes básicas de demanda: a demanda dependente e a independente. A demanda dependente é resultante da demanda de outros produtos ou serviços, enquanto a demanda independente não pode ser provocada pela necessidade de outros produtos e sim pela demanda direta do cliente.

Para o desenvolvimento da previsão de demanda, segundo Corrêa, Gianesi e Caon (2013), é necessário conhecer os próprios produtos e o mercado consumidor, formar uma base de dados para a previsão, saber analisar os dados, conhecer as 
ações da própria empresa que afetam a demanda, documentar hipóteses de venda, informar-se sobre a concorrência, articular os setores da empresa para a elaboração da previsão da demanda, conhecer e controlar todas as fontes e padrões de demanda, para que o sistema produtivo e todas as áreas funcionais tenham eficiência e o produto seja entregue pontualmente ao cliente.

\subsection{Padrões e Componentes de Demanda}

As demandas podem ter padrões diferentes podendo ser uma demanda terminal, perpétua, sazonal ou irregular. A demanda de padrão perpétuo é caracterizada por sua continuação no futuro infinito, embora ela cresça e diminua ao longo do tempo, possui venda suficientemente alongada para ser considerada infinita. (BALLOU, 2006)

A demanda com padrões de sazonalidade apresenta picos de vendas em determinados momentos do ano, alguns produtos como roupas de moda e árvores de natal, são exemplos de itens com demanda sazonal. Já a demanda de padrão irregular ou errático, apresenta períodos escassos seguidos por picos repentinos de demanda, sendo mais difícil de prever quando comparado com a demanda sazonal que geralmente acontece em uma determinada época do ano. Para distinguir as duas é preciso calcular o desvio padrão da distribuição de demanda ou o erro de previsão e se ele for maior que a demanda média ela é provavelmente uma demanda irregular. (BALLOU, 2006)

Outros produtos se esgotam em algum momento previsível no futuro não ficando no mercado por mais de um ano, sendo denominados de produtos de demanda terminada, exemplos desse padrão de demanda são livros didáticos com revisão já prevista e produtos farmacêuticos com limitada exposição nas gôndolas. Por fim, existe o padrão de demanda derivado, no qual a demanda de um produto é derivada da demanda de outro produto, como acontece com as embalagens que são derivadas da necessidade de produtos primários (BALLOU, 2006).

Segundo Fenerich (2016) plotando um gráfico de tempo versus demanda como mostra a Figura 1, é possível identificar o padrão da demanda. 
Figura 1 - Padrões de demanda

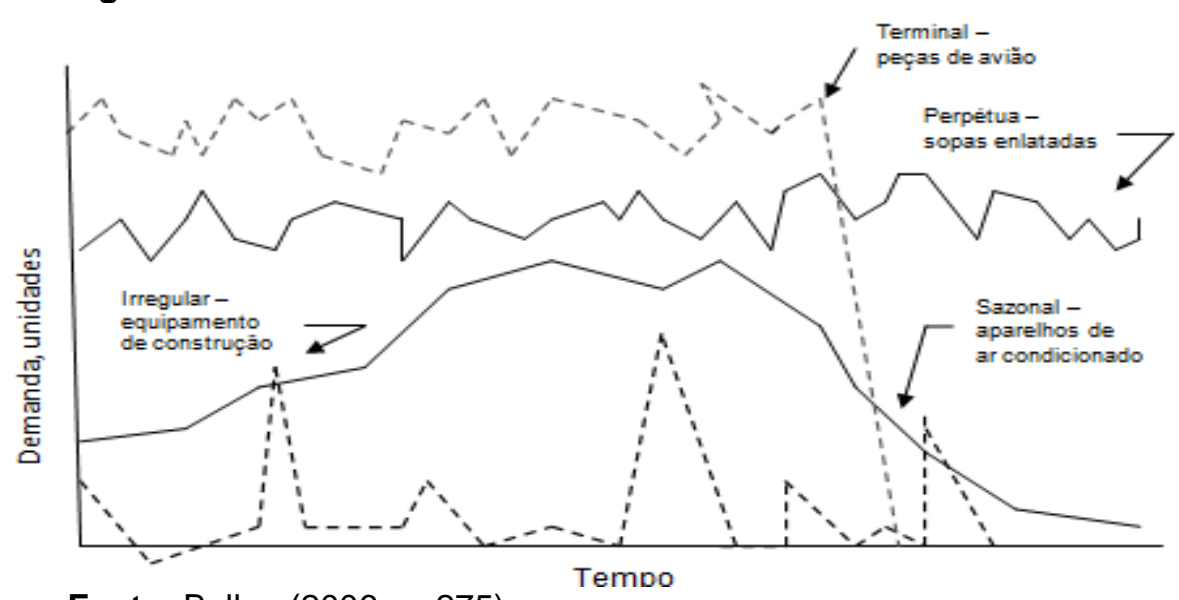

Fonte: Ballou (2006, p. 275)

Por meio da plotagem do gráfico de demanda versus tempo é possível observar os componentes de uma demanda que segundo Chase, Jacobs e Aquilano (2006) são: a demanda média do período, tendência, elementos sazonais, elementos cíclicos, variação aleatória e autocorrelação.

Segundo Fenerich (2016), a tendência representa o crescimento ou decrescimento constante, apresentando uma linearidade em uma angulação de reta que continuará no futuro. Para Chase, Jacobs e Aquilano (2006), a tendência pode ser linear, com relação reta e contínua; curva em S, típica da fase de crescimento e maturidade de um produto; assintótica que começa com um crescimento rápido, mas depois diminui e de curva exponencial que acontece com produtos com crescimento explosivo, sugerindo que as vendas vão continuar a aumentar como mostra a Figura 2.

De acordo com Krajewski, Ritzman e Malhotra (2009), a sazonalidade produz aumentos e reduções na demanda que podem ser repetidos em um determinado período futuro. Bem como a tendência e a sazonalidade que se combinam em graus variados e definem o comportamento da demanda de um produto ou serviço, como pode ser visto abaixo na Figura 3. 
Figura 2 - Tipos de tendência

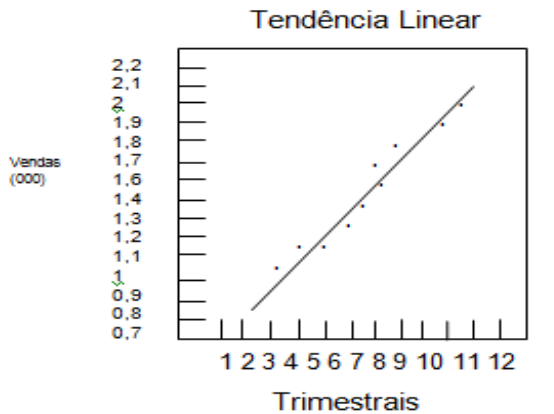

Tendência Assintótica

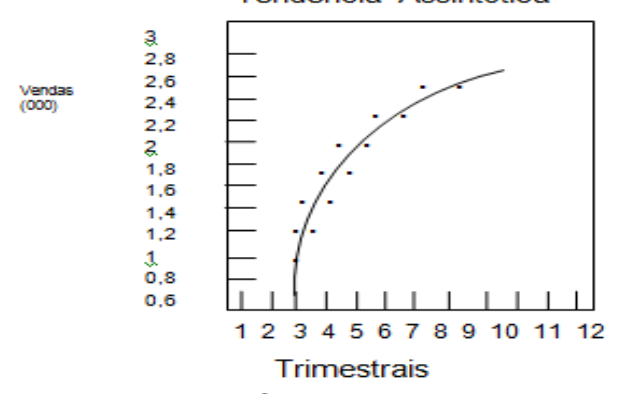

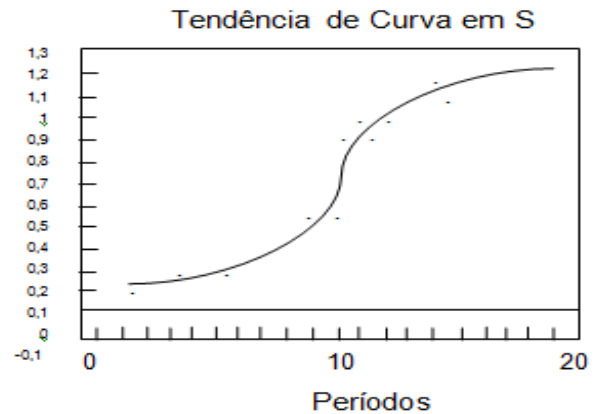

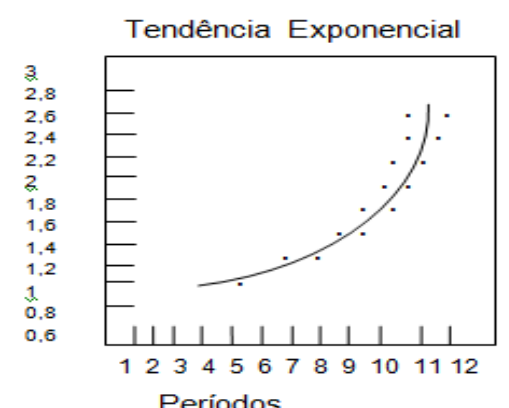

Fonte: Chase, Jacobs e Aquilano (2006, p.341)

Figura 3 - Demanda com sazonalidade e tendência Modelo sazonal

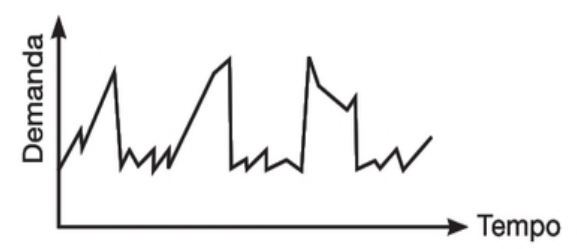

Modelo sazonal com tendência

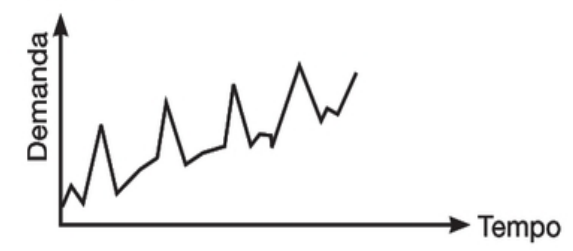

Fonte: Albertin e Pontes (2016, p. 34)

A influência cíclica na demanda gera alterações que se repetem em períodos longos de tempo normalmente vários anos ou décadas e isso pode acontecer devido a diferentes motivos como moda, condições econômicas, guerras e eleições políticas, um exemplo de produto cíclico, são as roupas que eram usadas na década de 60 e voltam à moda. A Figura 4 representa o comportamento da ciclicidade da demanda (CHASE; JACOBS; AQUILANO, 2006).

Figura 4 - Demanda com ciclos

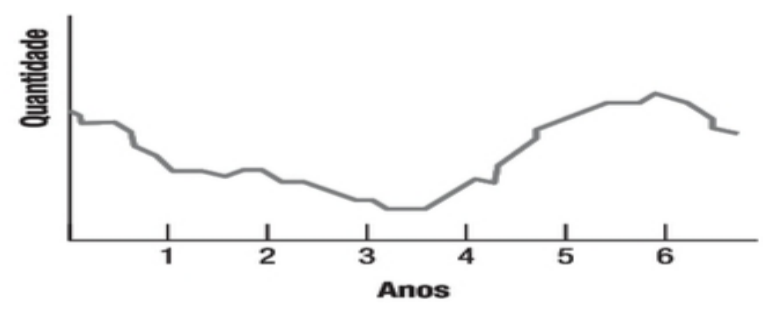

Fonte: Krajewski, Ritzman e Malhotra (2009, p. 438) 
As variações aleatórias são provocadas por eventos ao acaso, estatisticamente quando todas as causas conhecidas da demanda como tendência, média, sazonalidade, ciclo ou autocorrelação são tiradas da demanda, o que resta e não é identificada a sua causa é considerado como um evento puramente aleatório (CHASE; JACOBS; AQUILANO, 2006).

Por fim, a autocorrelação indica que o valor esperado em qualquer ponto é correlacionado aos valores do passado, dessa forma quando há autocorrelação, espera-se que a demanda não varie muito de uma semana para outra ao contrário da aleatoriedad. (CHASE; JACOBS; AQUILANO, 2006).

\subsection{Projeção da Demanda}

As previsões podem abranger horizontes de curto, médio e longo prazo da demanda futura, alguns métodos se mostram mais adequados para previsões mais longas projetando vários anos no futuro, enquanto outros são aplicados a previsões de períodos mais curtos como meses e semanas (MOREIRA, 2013).

A projeção da demanda futura é realizada modelando-se matematicamente os dados do passado e utilizando equações matemáticas para prever as vendas futuras. Geralmente, decompõem-se as vendas passadas em dois ou mais componentes que possam ser modelados, como em função de uma curva de tendência e fatores de sazonalidade, como mostra a Figura 5 (CORRÊA; GIANESI; CAON, 2013).

Posteriormente é feita a análise dos dados e a escolha de uma hipótese básica que pode ser: hipótese de permanência, em que se admite comportamento estável e uniforme da demanda, sem tendência ou sazonalidade identificada; hipótese sazonal com permanência, em que se admite a presença de sazonalidade identificada, mas sem tendência de acréscimo ou decréscimo na média das vendas; hipótese de trajetória, em que se admite que as vendas tem aumento ou decréscimo, mas sem sazonalidade identificada e hipótese sazonal com trajetória, que se admite a presença de sazonalidade que pode ser justificada e com tendência de aumento. Abaixo, a Figura 6 com as hipóteses de comportamento das vendas (CORRÊA; GIANESI; CAON, 2013). 
Figura 5 - Decomposição das vendas

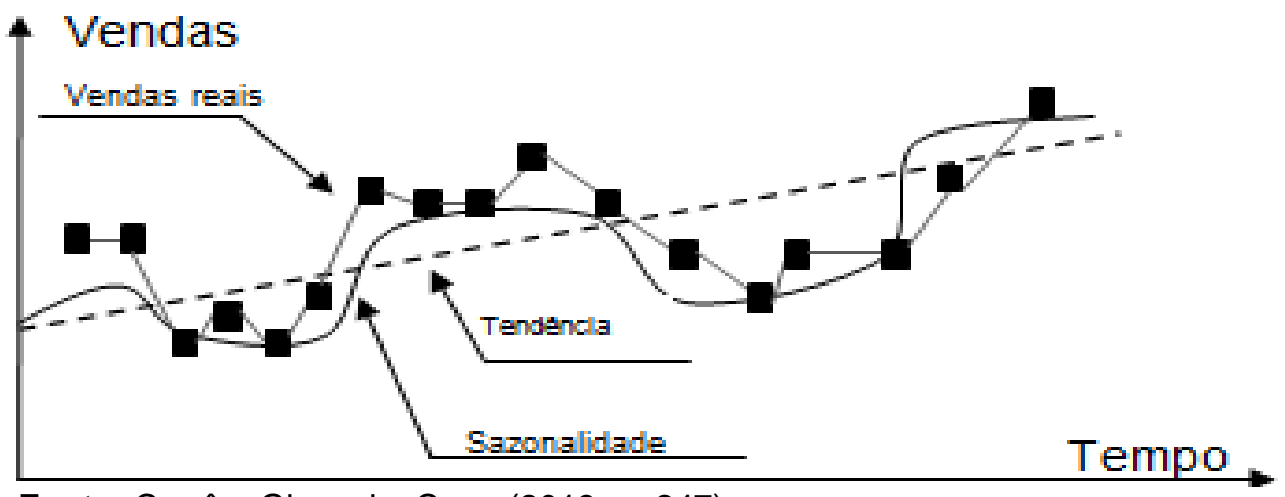

Fonte: Corrêa, Gianesi e Caon (2013, p. 247)

Figura 6 - Hipóteses de vendas
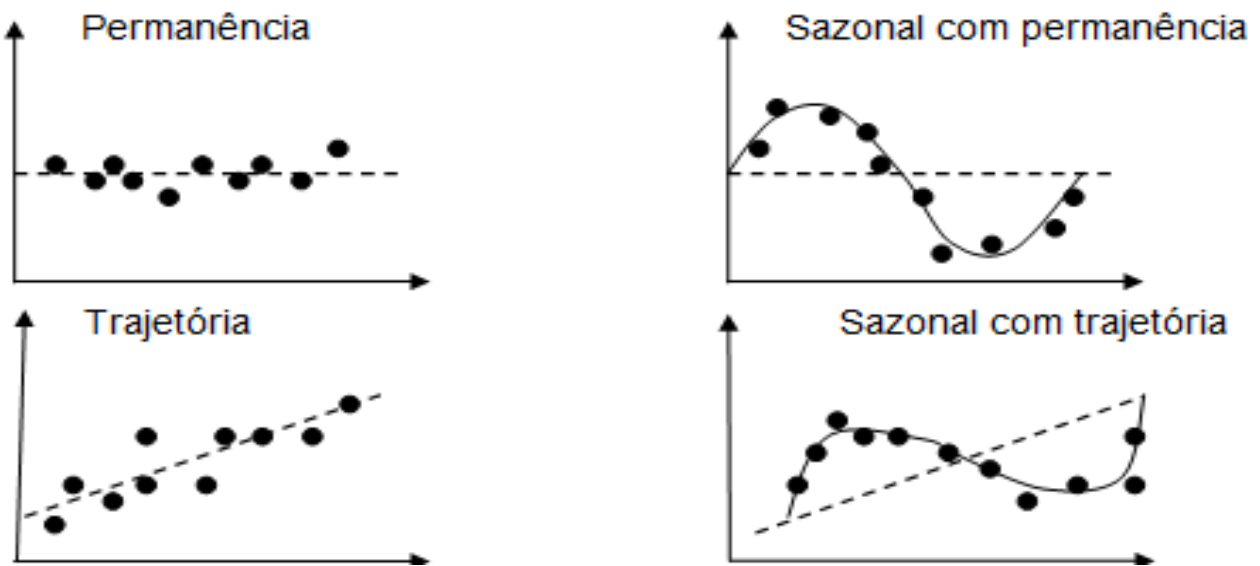

Fonte: Corrêa, Gianesi e Caon (2013, p. 247)

Depois de escolhida a hipótese deve-se escolher o método mais adequado. Geralmente os métodos mais adequados para previsão de curto prazo são a média móvel e a suavização exponencial.(CORRÊA; GIANESI; CAON, 2013)

Quando o horizonte de previsão começa a aumentar, a hipótese de que o futuro vai repetir o passado deixa de ser válida, buscando se estudar o comportamento da demanda do que fazer uma simples correlação com o tempo. Nesse caso a análise feita depois do tratamento matemático passa a ser mais importante do que o método, procurando estabelecer relações entre as vendas no passado e as variáveis que expliquem seu comportamento. Para horizontes de prazo médio, os melhores métodos são o causal ou de suavização exponencial (CORRÊA; GIANESI; CAON, 2013). 
Para horizontes de tempo ainda maiores, de vários anos, de acordo com Chopra e Meindl (2016), as previsões são menos precisas do que previsões de curto prazo, ou seja, as previsões de longo prazo tem maior desvio padrão de erro em relação à média do que as de curto prazo, sendo que para esse caso, segundo Corrêa, Gianesi e Caon (2013) a hipótese de que as relações que havia no passado entre a demanda e outras variáveis que explicavam seu comportamento deixam de ser válidas, por conta das mudanças tecnológicas ou a introdução de novos produtos que alteram as relações válidas anteriormente.

Dessa forma não se considera que o futuro tem relação direta com o passado, pelo menos não uma relação que possa ser modelada matematicamente, a previsão deve ser derivada de opiniões de especialistas, a fim de conseguir um consenso sobre as opiniões para utilização de métodos específicos. Nesse horizonte de tempo, modelos temporais e causais podem ser utilizados desde que se analisem as hipóteses adotadas e determine peso grande à mesma (CORRÊA; GIANESI; CAON, 2013).

\subsection{Métodos de Previsão de Demanda}

Os métodos quantitativos utilizam métodos matemáticos para realizar a previsão, necessitando de informações quantitativas preliminares. Elas são baseadas em dados históricos de vendas e em variáveis correlacionadas às vendas, buscando a quantificação dessas variáveis que estão relacionadas e influenciam as vendas (FENERICH, 2016).

Os métodos quantitativos subdividem-se em: métodos causais e séries temporais. Nos métodos causais a demanda de um item ou de uma família de itens é relacionada a uma ou mais variáveis internas ou externas da organização, que são denominadas de variáveis causais, admitindo-se que é mais fácil prever o comportamento das variáveis do que da própria demanda. As variáveis causais são escolhidas por meio da ligação lógica que elas têm com a demanda (MOREIRA, 2013).

Enquanto que a série temporal é uma sequência de observações da demanda ao longo do tempo, sendo as observações espaçadas igualmente como dias, 
semanas, meses, trimestres, semestres ou anos. Nessa técnica a demanda não é associada a qualquer outra variável da qual supostamente possa depender, já que a hipótese básica é de que os valores futuros das séries podem ser estimados com base nos valores passados (MOREIRA, 2013).

Para Krajewski, Ritzman e Malhotra (2009), esse método é baseado na suposição de que o padrão anterior continuará no futuro, demonstrando que os padrões das demandas anteriores podem gerar um histórico que possibilita o desenvolvimento de um modelo para replicá-lo. Entre os métodos de séries temporais mais utilizadas estão as médias e suavizações exponenciais.

\subsubsection{Média simples}

No método de média simples, a demanda é calculada como a média aritmética dos dados históricos, por meio da seguinte equação:

$$
\mathrm{Ft}+1=\frac{1}{\mathrm{t}} \cdot \sum_{t+1}^{t} Y i
$$

\footnotetext{
Sendo: $\mathrm{t}=$ período atual $\left(\mathrm{n}^{\circ}\right.$ de períodos conhecidos)

$Y i=$ demanda no período $\mathrm{i}$

$\mathrm{Ft}_{\mathrm{t}}+1=$ previsão para o período seguinte
}

\subsubsection{Média móvel simples}

Segundo Moreira (2013), esse método segue a premissa de que o período t, imediatamente futuro, é obtido por meio da média aritmética dos $n$ valores reais da demanda passada.

A média móvel simples pode ser eficiente quando a demanda varia em torno de um valor médio, para demandas crescentes ou decrescentes ao longo do tempo, ela possui desvantagens, fornecendo sempre uma previsão com atraso em relação aos valores reais, dessa forma se a demanda é crescente, as previsões darão valores cada vez menores em relação aos valores reais, bem como não é eficiente para variações sazonais podendo acobertá-las (MOREIRA, 2013). 
Dessa forma, ela é utilizada para a demanda de um produto que não aumente nem diminua rapidamente, que não apresente assim características sazonais e que não estejam em fase de crescimento ou declínio no ciclo de vida. A fórmula de média móvel simples pode ser vista na equação:

$$
\mathrm{Ft}+1=\frac{1}{\mathrm{n}} \cdot \sum_{i=t-n+1}^{t} Y i
$$

Sendo: $\mathrm{Ft}+1$ = previsão para o período seguinte

$\mathrm{n}=$ número de períodos recentes a serem considerados na média

$\mathrm{t}=$ período atual

$Y i=$ demanda no período $\mathrm{i}$

\subsubsection{Suavização exponencial simples}

Segundo Ritzman e Krajewski (2004) a suavização exponencial pressupõe que a demanda oscila em torno de um patamar ou demanda base constante, sendo muito utilizada por causa de sua simplicidade e do pequeno número de dados necessários. A suavização requer três tipos de dados: a previsão do último período, a demanda para esse período e um parâmetro de aproximação alfa ( $\alpha$ ), que tem valor entre 0 e 1 . Para obter uma previsão com suavização exponencial, calcula-se a previsão e a demanda obtida no último período. A equação para a previsão de demanda por meio da suavização exponencial simples é:

$F_{t+1}=\alpha \cdot Y t+(1-\alpha) \cdot F_{t}$

Sendo: $F_{t+1}=$ previsão para o período seguinte

$\mathrm{F}_{\mathrm{t}}=$ previsão calculada para o período atual, realizada no período anterior

$\mathrm{Y}_{\mathrm{t}}=$ demanda no período atual

$\alpha=$ constante de ponderação exponencial

Ela indica que a previsão para o próximo período é igual á previsão para o período atual mais uma proporção dos erros para o período atual de previsão. A 
ênfase dada aos níveis mais recentes de demanda pode ser ajustada alterando o parâmetro de aproximação ( $\alpha$ ), sendo que ele determina se a curva de projeção será mais ou menos suave, os valores próximos de zero implicam em menores correções da base, que irão resultar em uma curva de projeção mais suave tratando a demanda passada de modo mais uniforme e resultando em previsões mais estáveis, enquanto que valores próximos ao valor um, produzem maiores correções e enfatizam as demandas mais recentes, resultando em previsões mais sensíveis a alterações na média básica. Na prática são experimentados vários valores de a e escolhe-se aquele que produz uma melhor previsão (RITZMAN; KRAJEWSKI, 2004).

Segundo Chase, Jacobs e Aquilano (2006), o valor da constante é determinado pela natureza do produto e pelo conhecimento do gerente, por exemplo, se uma empresa fabrica um item com uma demanda relativamente estável, o índice de reação às diferenças entre a demanda real e prevista seria pequeno em torno de 0,05 ou 0,1, mas se o produto está em fase de crescimento de vendas, seria desejável um índice mais alto de 0,15 a 0,3 com o objetivo de atribuir maior importância ao crescimento recente das vendas.

O ideal seria se fosse possível prever qual alfa usar, mas as demandas mudam e o alfa escolhido agora pode precisar ser revisado, sendo necessário um método automático para acompanhar e modificar os valores de $\alpha$. Para isso existem duas técnicas, a de dois ou mais valores predeterminados de alta, no qual dependendo do tamanho do erro entre a previsão e a realidade da demanda, valores são usados, como para erros grandes é utilizado $\alpha$ de 0,8 e erros pequenos $\alpha$ de 0,2 e a técnica de valores calculados de alfa, que um alfa de rastreamento, calcula se a previsão está acompanhando mudanças reais na demanda ou não, sendo a definido como o erro real suavizado, dividido pelo erro absoluto suavizado (CHASE; JACOBS; AQUILANO, 2006).

A suavização exponencial necessita de uma previsão inicial, que pode ser obtida de duas formas: usando a demanda do último período ou calculando a média de diversos períodos recentes da demanda. Ela possui vantagens por ser simples, exigir poucos dados históricos e ser econômica de usar, sendo atrativa para as empresas que realizam milhares de previsões a cada período de tempo (RITZMAN; KRAJEWSKI, 2004). 


\subsubsection{Suavização exponencial com tendência - Método de Holt}

Segundo Chase, Jacobs e Aquilano (2006) uma demanda com tendência de crescimento ou declínio faz com que as previsões suavizadas exponencialmente sempre fiquem defasadas em relação a realidade, projetando demandas maiores ou menores do que a realidade. Assim para corrigir a tendência surge a suavização exponencial com tendência, utilizando duas constantes de suavizamento. Além da constante de suavização alfa ( $\alpha$ ) é utilizada uma constante de suavizamento beta $(\beta)$, essa reduz o impacto do erro que ocorre entre o real e o previsto. A equação para o cálculo da previsão com tendência é:

$$
\begin{aligned}
& L T=\alpha \cdot Y_{t}+(1-\alpha) \cdot\left(L_{t}+b_{t-1}\right) \\
& b_{t}=\beta \cdot\left(L_{t}+L_{t-1}\right)+(1-\beta) \cdot\left(b_{t-1}\right) \\
& F_{t+m}=L_{t}+m \cdot b_{t}
\end{aligned}
$$

$$
\begin{aligned}
& \text { Sendo: } L T=\text { base da série no período } t \\
& \alpha=\text { constante de ponderação exponencial para base } \\
& Y_{t}=\text { demanda do período atual } \\
& b_{t}=\text { tendência da série no período } t \\
& \beta=\text { constante de ponderação exponencial para a tendência } \\
& F_{t+m}=\text { previsão para } m \text { períodos a frente }
\end{aligned}
$$

De acordo com Ritzman e Krajewski (2004), para realizar as previsões é necessário multiplicar a estimativa da tendência pelo número de períodos adicionais que se deseja na previsão e somar os resultados à média atual. As estimativas para a média e tendência do último período necessária para a primeira previsão podem ser conseguidas por meio de dados passados ou serem baseadas em suposições caso não existam dados históricos. Já para os valores de $\alpha$ e $\beta$, geralmente um analista ajusta sistematicamente os valores até que os erros de previsão sejam os menores possíveis. 
O método de suavização exponencial com tendência e sazonalidade incorpora além da tendência um componente de sazonalidade, com objetivo de projetar a demanda base $(\mathrm{Bt})$ calculada por meio da fórmula abaixo, calcular a tendência e extrair os efeitos da sazonalidade, mediante o índice de sazonalidade $\left(\mathrm{S}_{\mathrm{t}}\right)$ que será uma média ponderada entre o real observado e o índice anterior e por fim para obter a previsão multiplica-se a projeção da demanda base pelo índice de sazonalidade correspondente. Sendo que s é a extensão do ciclo sazonal, por exemplo, trabalhando com unidade de tempo mês e ciclo sazonal anual, $L=12$. (MESQUITA, 2008)

$$
\begin{aligned}
& \mathrm{L}_{\mathrm{t}}=\alpha \cdot \frac{Y t}{\mathrm{~S}_{\mathrm{t}-s}}+(1-\alpha) \cdot\left(\mathrm{L}_{\mathrm{t}-1}+\mathrm{b}_{\mathrm{t}-1}\right) \\
& \mathrm{b}_{\mathrm{t}}=\beta \cdot\left(\mathrm{L}_{\mathrm{t}-1}+\mathrm{b}_{\mathrm{t}-1}\right)+(1-\beta) \cdot \mathrm{B}_{\mathrm{t}-1} \\
& \mathrm{~S}_{\mathrm{t}}=\mathrm{Y} \cdot \frac{Y t}{\mathrm{~L}_{\mathrm{t}}}+(1-\mathrm{Y}) \cdot \mathrm{S}_{\mathrm{t}-\mathrm{s}} \\
& \mathrm{F}_{\mathrm{t}+\mathrm{m}}=\left(\mathrm{L}_{\mathrm{t}}+\mathrm{m} \mathrm{b}_{\mathrm{t}}\right) \cdot \mathrm{S}_{\mathrm{t}-\mathrm{s}+\mathrm{m}}
\end{aligned}
$$

$$
\begin{aligned}
& \text { Sendo: } \mathrm{L}_{\mathrm{t}}=\text { base da série no período } \mathrm{t} \\
& \alpha=\text { constante de ponderação exponencial para a base } \\
& Y t=\text { demanda do período atual } \\
& \mathrm{b}_{\mathrm{t}}=\text { tendência da série no período } \mathrm{t} \\
& \beta=\text { constante de ponderação exponencial para tendência } \\
& \mathrm{S}_{\mathrm{t}}=\text { sazonalidade da série no período } \mathrm{t} \\
& \mathrm{Y}=\text { constante de ponderação exponencial para sazonalidade } \\
& \mathrm{S}=\text { comprimento da sazonalidade } \\
& \mathrm{m}=\text { número de períodos a frente para previsão } \\
& \mathrm{F}_{\mathrm{t}+\mathrm{m}}=\text { previsão para } \mathrm{m} \text { períodos a frente }
\end{aligned}
$$

Os índices de sazonalidade iniciais podem ser feitos considerando o primeiro ciclo sazonal da série e fixando para cada mês a razão entre a demanda de cada mês e do período. (MESQUITA, 2008) 


\subsection{Erros de Previsão}

Após o conhecimento dos métodos de previsão é preciso escolher qual é o melhor a ser aplicado. Para isso deve-se saber que o método ideal será aquela que melhor representar a variação da demanda configurada no período de dados históricos. Dessa forma, quanto menor o erro de previsão isso é, o erro entre o valor real e o previsto, mais próxima da curva de demanda real o método estará (GONÇALVES, 2013).

Para isso existem várias formas de medir os erros da previsão e para o estudo foi utilizado o erro absoluto percentual médio (MAPE) que representa a média percentual da divisão entre erro de previsão e o valor real para verificar a adequação do modelo de previsão.

$$
\frac{\mathrm{MAPE}=\sum\left|\frac{\mathrm{Dt}-\mathrm{Ft}}{\mathrm{Dt}}\right| \times 100}{\mathrm{n}}
$$

Sendo: $\mathrm{Dt}=$ demanda real para o período $\mathrm{t}$

$\mathrm{Ft}=$ previsão para o período $\mathrm{t}$

$\mathrm{n}=$ períodos

\section{PROCEDIMENTOS METODOLÓGICOS}

O estudo propõe uma pesquisa quantitativa, com a simulação de métodos quantitativos de previsão de demanda. Segundo Martins (2012) nessa abordagem o pesquisador captura as evidências da pesquisa por meio da mensuração das variáveis envolvidas, sem nenhum subjetivismo nos fatos e na geração de conhecimento, já que o pesquisador não interfere nas variáveis de pesquisa, sendo as mesmas oferecidas pela natureza ou derivada de uma teoria consolidada ou provisória.

O estudo foi iniciado com a pesquisa bibliográfica para obtenção de conhecimento e construção de um raciocínio crítico sobre os métodos de previsão de demanda. Posteriormente foram coletados dados referentes ao histórico de vendas da organização, mas especificamente, a quantidade vendida mensalmente de cada família de produtos durante o período de janeiro de 2014 à dezembro de 2016, sendo essas informações extraídas por meio dos relatórios mensais de vendas realizados 
pela empresa e agrupados em famílias de produtos que permitiram verificar e analisar a demanda histórica de cada grupo de produtos.

Com o conhecimento da demanda histórica e do comportamento da mesma, foram testados a partir de codificação em Visual Basic Applications (VBA) alguns métodos de previsão de demanda, sendo eles, Média Simples, Média Móvel, Suavização Exponencial, Suavização Exponencial com Tendência - Método de Holt e Suavização Exponencial com Tendência e Sazonalidade - Método de Holt-Winters que permitiram a análise e identificação dos métodos mais adequados à realidade dos dados e ao cenário atual da empresa, sendo que os melhores métodos foram os que apresentaram o menor MAPE, isto é, os métodos que geraram a menor diferença entre o valor real e o previsto de demanda em cada família de produto.

As codificações são conjuntos de ações predefinidas para serem executadas a partir de um comando, enquanto que o Visual Basic Applications (VBA) consiste em uma plataforma de programação que funciona em segundo plano nos programas do Office, como no Excel, ampliando suas funcionalidades e permitindo a criação de macros personalizados.

\section{RESULTADOS E DISCUSSÕES}

Os resultados obtidos de previsão de demanda são decorrentes do histórico de vendas mensais entre janeiro de 2014 a dezembro de 2016, cedido pela organização, totalizando 36 meses de dados, o que de acordo com a literatura é o valor mínimo ideal de vendas a ser utilizado, para que se tenha 24 meses como base histórica e os últimos 12 meses como parâmetro para medição do erro.

A previsão de demanda foi realizada para seis famílias de produtos da organização, sendo essa divisão dos itens em famílias de produtos realizada pela própria empresa, por conta da mesma possuir uma diversidade de itens fabricados que necessitaram ser agrupados para realização das previsões. Dessa forma, as famílias de produtos foram compostas por itens com características parecidas, sendo elas: família de artigos para natação, meias, artigos fitness, artigos de dance wear, calçados e bolsas.

Para cada uma das seis famílias de produtos foram testados os métodos de 
série temporal de previsão de demanda da Média Simples, Média Móvel, Suavização Exponencial, Suavização Exponencial com Tendência - Método de Holt e Suavização Exponencial com Tendência e Sazonalidade - Método de Holt-Winters e calculado o MAPE de cada um dos métodos de previsão de demanda testado em cada família de produtos.

Para o cálculo da Média Simples foram considerados os 24 primeiros meses como base histórica de vendas, isto é, as vendas do período entre janeiro de 2014 a dezembro de 2015 e os últimos 12 meses, que correspondem de janeiro de 2015 a dezembro do mesmo ano, utilizados como parâmetro para medição do erro absoluto percentual médio e obtida as previsões a partir do mês de março de 2014 até dezembro de 2016.

Para o método de Média Móvel, foi considerado o mesmo princípio utilizandose dos 24 primeiros meses como base histórica de vendas e os últimos 12 meses para cálculo do MAPE. Para cálculo das previsões de demanda foram testados diferentes intervalos de tempo, isto é, valores para n que variaram entre 2 a 24, por conta do princípio utilizado de 24 meses de base histórica de dados, para possibilitar a identificação do intervalo de tempo que resulta em uma previsão mais próxima da realidade.

Para a previsão de demanda realizada com o método de Suavização Exponencial foi utilizada a média do histórico de demanda de janeiro de 2014 a dezembro de 2014 como valor inicial para a previsão, considerados os 24 primeiros meses como base histórica e adotado os 12 últimos meses como parâmetro para o cálculo do MAPE. No método foram testados, a partir de macros em Visual Basic Applications (VBA), diferentes valores para o alfa que variaram de 0 a 1 , numa escala de 1000, com o objetivo de identificar o melhor valor de alfa, cujo valor é o que gera a previsão de demanda dos últimos 12 meses de menor erro absoluto percentual médio.

Na previsão de demanda a partir do método de Suavização Exponencial com Tendência - Método de Holt, foram testados, a partir de macros em Visual Basic Applications (VBA) diferentes valores para o alfa e beta entre 0 e 1, numa escala de 500 , a fim de identificar a combinação das constantes que resultasse o menor MAPE. No método foi necessário calcular uma base, que adotou como valor inicial a média do histórico de vendas de janeiro de 2014 à dezembro de 2014, calculou-se também 
a tendência prevista que iniciou-se com o valor de zero, para o mês de janeiro, a diferença entre a base prevista entre janeiro e fevereiro, para valor de tendência prevista de fevereiro e para os meses seguintes foi utilizada a fórmula de suavização da tendência já mencionada no seguinte estudo e por fim, a soma da base prevista e da tendência prevista de cada mês anterior, resultou na previsão de demanda.

Já o método de Suavização Exponencial com Tendência e Sazonalidade Método de Holt-Winters necessita do cálculo da base, tendência e sazonalidade e para isso foram testados, a partir de macros em Visual Basic Applications (VBA) diferentes valores para o alfa, beta e gama entre 0 e 1, numa escala de 50, com 0 objetivo de identificar a combinação que resultasse o menor MAPE. Para a base foram considerados para os 12 primeiros meses, isso é, de janeiro de 2014 a dezembro do mesmo ano, um mesmo valor, que é o da média da demanda entre janeiro de 2014 a dezembro de 2014 e nos meses seguintes aplicada a fórmula do método. Já a tendência foi iniciada com o valor de zero em janeiro de 2014, em fevereiro o valor utilizado foi a diferença dos valores da base de janeiro e fevereiro de 2014, e a partir de março, aplicada a fórmula do método, enquanto que a sazonalidade dos 12 primeiros meses foi calculada pela divisão da demanda do período pela média da demanda por 12 primeiros meses e a sazonalidade dos meses restantes aplicada a fórmula do método. Nesse método a previsão foi o resultado da soma da base e sazonalidade do período, multiplicada pela tendência.

Após a aplicação dos métodos na família de bolsas foram obtidos os seguintes resultados observados na Tabela 1 .

Tabela 1 - Resultado dos MAPEs de cada um dos métodos de previsão de demanda testados para a família de bolsas

\begin{tabular}{|c|c|c|c|c|c|}
\hline \multicolumn{6}{|c|}{ FAMÍLIA DE BOLSAS } \\
\hline MÉTODOS DE PREVISÃO DE DEMANDA & $\mathbf{n}$ & $\alpha$ & B & $\mathbf{y}$ & MAPE \\
\hline Média Simples & & & & & $53,00 \%$ \\
\hline Média Móvel & 7 & & & & $51,62 \%$ \\
\hline Suaviz. Expon. & & 1,0 & & & $51,15 \%$ \\
\hline Suaviz. Expon. com Tendência - Método de Holt & & 1,0 & 0,058 & & $52,60 \%$ \\
\hline $\begin{array}{l}\text { Suaviz. Expon. com Tend. e Saz. - Método de } \\
\text { Holt-Winters }\end{array}$ & & 0,1 & 0,9 & 1,0 & $29,40 \%$ \\
\hline
\end{tabular}

Fonte: Própria autora 
O método da Média Simples se mostrou o menos indicado para a previsão de demanda da família de bolsas da organização, por ter projetado uma previsão de demanda com o maior erro absoluto médio entre os métodos testados, gerando um MAPE de 53,00\%, acompanhado dele, o método da Suavização Exponencial com Tendência - Método de Holt, proporcionou também uma previsão de demanda com alto erro, nesse caso, um MAPE de 52,60\%. Outro método que demonstrou grandes erros de previsão foi a média móvel, que após cálculos o menor MAPE possível encontrado foi de $51,62 \%$ por meio da utilização de um intervalo de tempo de sete meses, demonstrando grande margem de erro, assim como a Suavização Exponencial que obteve um valor de MAPE, parecido com o método de média móvel, demonstrando grandes diferenças entre a projeção da demanda futura.

Assim o melhor método de previsão de demanda para a família de bolsa encontrado foi a Suavização Exponencial com Tendência e Sazonalidade - Método de Holt-Winters que gerou uma previsão com o menor erro absoluto médio de 29,40\% e ao contrário dos métodos anteriores utilizou um baixo valor para alfa para a projeção futura como pode ser visto na Figura 7.

O método resultou nessa previsão, utilizando o valor de $\alpha=0,1$, nesse caso, enfatizando as demandas passadas do histórico e produzindo menores correções nas irregularidades ao longo da base de dados de vendas, diferentemente dos métodos anteriores e atribuindo maior valor ao beta, $\beta=0,9$, que foi usado para suavizar as variações da inclinação da tendência, assim como para gama, que após os testes o melhor valor considerado foi $\gamma=1,0$, sendo o valor máximo possível de ser utilizado na constante, demonstrando grandes correções realizadas na sazonalidade para projeção da demanda, já que é possível observar na Figura 7, que a mesma é a principal característica da demanda dessa família de produtos. 
Figura 7 - Demanda X Previsão de demanda mensal obtida com a aplicação do método de Suavização Exponencial com Tendência e Sazonalidade - Método de Holt-Winters na família de bolsas

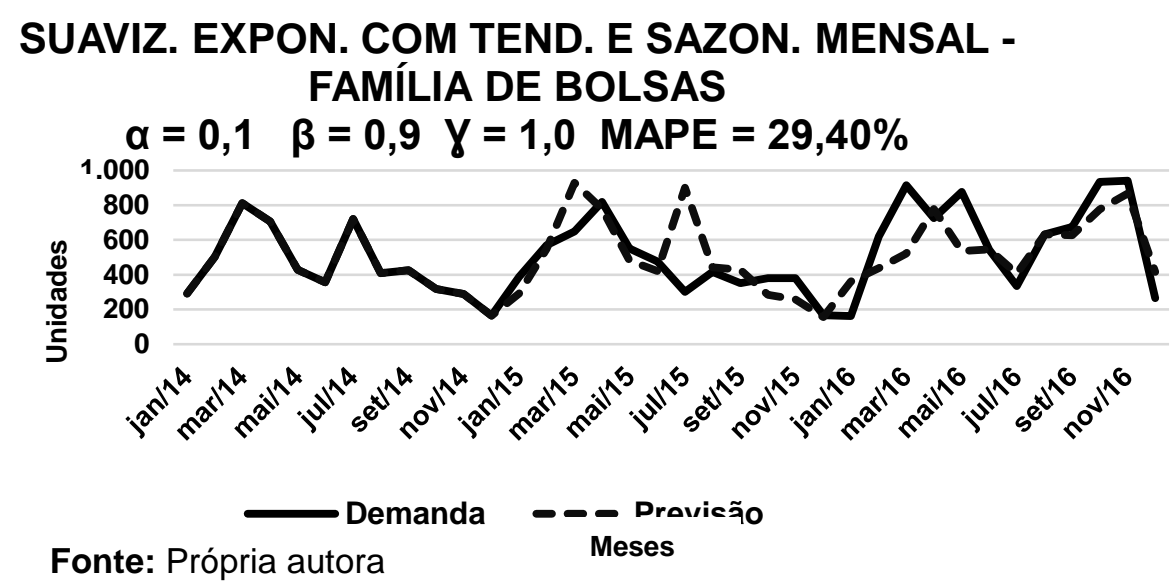

Já na família de calçados foram obtidos os seguintes resultados observados na Tabela 2.

Tabela 2 - Resultado dos MAPEs de cada um dos métodos de previsão de demanda testados para a família de calçados

\begin{tabular}{|c|c|c|c|c|c|}
\hline \multicolumn{6}{|c|}{ FAMÍLIA DE CALÇADOS } \\
\hline MÉTODOS DE PREVISÃO DE DEMANDA & $\mathbf{n}$ & $\alpha$ & $\beta$ & $\gamma$ & MAPE \\
\hline Média Simples & & & & & $19,00 \%$ \\
\hline Média Móvel & 6 & & & & $15,85 \%$ \\
\hline Suaviz. Expon. & & 0,15 & & & $17,37 \%$ \\
\hline $\begin{array}{l}\text { Suaviz. Expon. com Tendência-Método } \\
\text { de Holt } \mathrm{Holt}^{-}\end{array}$ & & 0,02 & 1,0 & & $14,50 \%$ \\
\hline $\begin{array}{l}\text { Suaviz. Expon. com Tend. e Saz. - Método } \\
\text { Método de Holt-Winters }\end{array}$ & & 0,10 & 0,3 & 0,9 & $10,20 \%$ \\
\hline
\end{tabular}

Fonte: Própria autora

O método de Média Simples se mostrou novamente o menos indicado para a previsão de demanda, dessa vez para a família de calçados, por ter gerado a previsão de demanda com o maior erro absoluto médio de $19,00 \%$, assim como a Suavização Exponencial que demonstrou após testes, MAPE $=17,37 \%$.

A média móvel também não demonstrou ser o melhor método para essa família de produtos, com o menor erro de previsão encontrado de MAPE $=15,85 \%$, conseguido por meio de um intervalo de tempo para cálculo de $n=6$, assim como, a Suavização Exponencial com Tendência - Método de Holt com MAPE de 14,50\%. Por fim, novamente o melhor método se mostrou ser o de Suavização Exponencial com Tendência e Sazonalidade - Método de Holt-Winters agora para a família dos 
calçados, gerando uma previsão com o menor erro absoluto médio de 10,20\% que pode ser visto na Figura 8.

Figura 8 - Demanda X Previsão de demanda mensal obtida com a aplicação do método de Suavização Exponencial com Tendência e Sazonalidade - Método de Holt-Winters na família de calçados

SUAVIZ. EXPON. COM TEND. E SAZON. MENSAL FAMÍLIA DE CALÇADOS

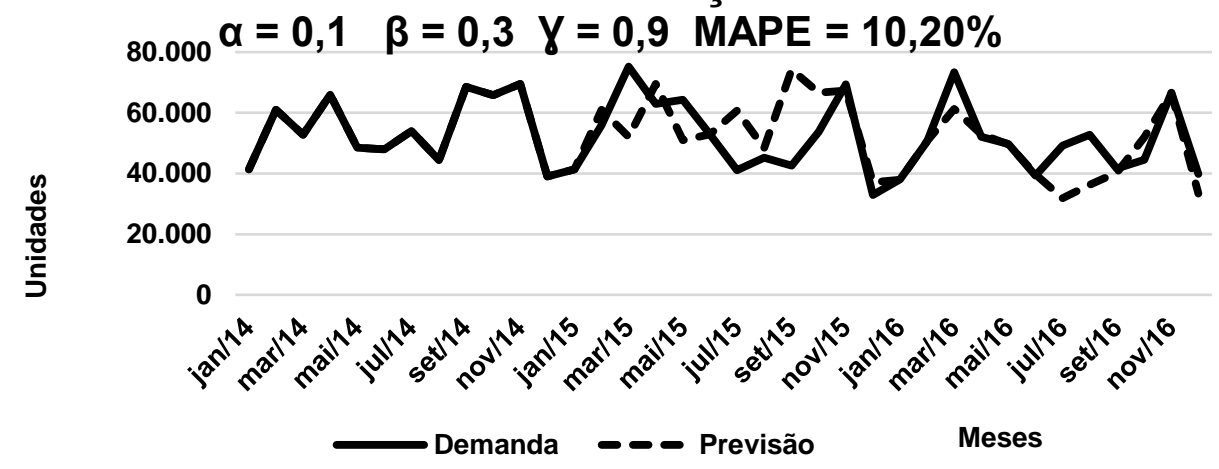

Fonte: Própria autora

Neste método, assim como nos anteriores dessa família de produtos, utilizouse um pequeno valor de alfa, neste caso de $\alpha=0,1$, trazendo maior peso as demandas passadas do histórico, assim como beta que também obteve um pequeno valor, $\beta=$ 0,3 que foi usado para suavizar as variações da inclinação da tendência, com menores correções e já a constante de sazonalidade, obteve maior valor $\gamma=0,9$, realizando grande suavização na sazonalidade por conta da família demonstrar grande sazonalidade.

Após o teste dos métodos na família de Dance Wear foram obtidos os seguintes resultados observados na Tabela 3.

Tabela 3 - Resultado dos MAPEs de cada um dos métodos de previsão de demanda testados para a família de dance wear

\begin{tabular}{lccccc}
\multicolumn{2}{c}{ FAMÍLIA DE DANCE WEAR } & & \\
MÉtodos DE PREVISÃO DE DEMANDA & $\mathbf{n}$ & $\boldsymbol{\alpha}$ & $\boldsymbol{\beta}$ & $\boldsymbol{\gamma}$ & MAPE \\
\hline Média Simples & 2 & & & $64,00 \%$ \\
Média Móvel & & & & $41,00 \%$ \\
Suaviz. Expon. & 1,0 & & & $38,61 \%$ \\
Suaviz. Expon. com Tendência - Método & 0,02 & 1,0 & & $34,30 \%$ \\
de Holt & & & & \\
Suaviz. Expon. com Tend. e Saz. - & 0,1 & 0,1 & 0,9 & $5,60 \%$ \\
Método de Holt-Winters & & & & \\
\hline
\end{tabular}

Fonte: Própria autora 
O método de Média Simples resultou em uma previsão com MAPE $=64,00 \%$, o maior erro entre os métodos testados para a família de Dance Wear, se mostrando o menos apropriado para realizar as previsões, assim como a média móvel que também não demonstrou ser o melhor método, com o menor erro encontrado de MAPE $=41,00 \%$, obtido por meio de um intervalo de tempo para cálculo de $n=2$, assim como a Suavização Exponencial que após testes resultou na melhor previsão do método com MAPE $=38,61 \%$.

A previsão baseada no método de Suavização Exponencial com Tendência Método de Holt demonstrou menor erro comparado com os métodos anteriores desta família de produtos, com MAPE de 34,30\%.

Entretanto o melhor método encontrado foi de Suavização Exponencial com Tendência e Sazonalidade - Método de Holt-Winters que gerou uma previsão com um erro bem inferior aos métodos testados anteriormente, gerando uma projeção com MAPE de apenas 5,60\% que pode ser visto na Figura 9.

A previsão gerada foi resultado da utilização do valor de $\alpha=0,1$, projetando uma demanda que atribuiu maior peso as demandas passadas do histórico, enquanto que o beta foi de $\beta=0,1$ usado para suavizar pouco as variações da inclinação da tendência e a constante de sazonalidade foi de $\gamma=0,9$ recebendo maior peso $\mathrm{e}$ realizando maiores correções em relação a sazonalidade para a projeção da demanda.

Após o teste dos métodos na família de artigos fitness foram obtidos os seguintes resultados observados na Tabela 4.

O método de Média Simples se mostrou o menos apto, gerando uma previsão longe da realidade dos produtos, com MAPE de 70,00\%, enquanto que a previsão de média móvel resultou em uma projeção melhor do que o método anterior com MAPE de $40,03 \%$ com o intervalo para conseguir esse valor sendo de $n=7$, já a Suavização Exponencial proporcionou uma previsão com erro de MAPE $=35,13 \%$ e a Suavização Exponencial com Tendência - Método de Holt erro de 33,50\%. 
Figura 9 - Demanda $X$ Previsão de demanda mensal obtida com a aplicação do método de Suavização Exponencial com Tendência e Sazonalidade - Método de Holt-Winters na família de dance wear

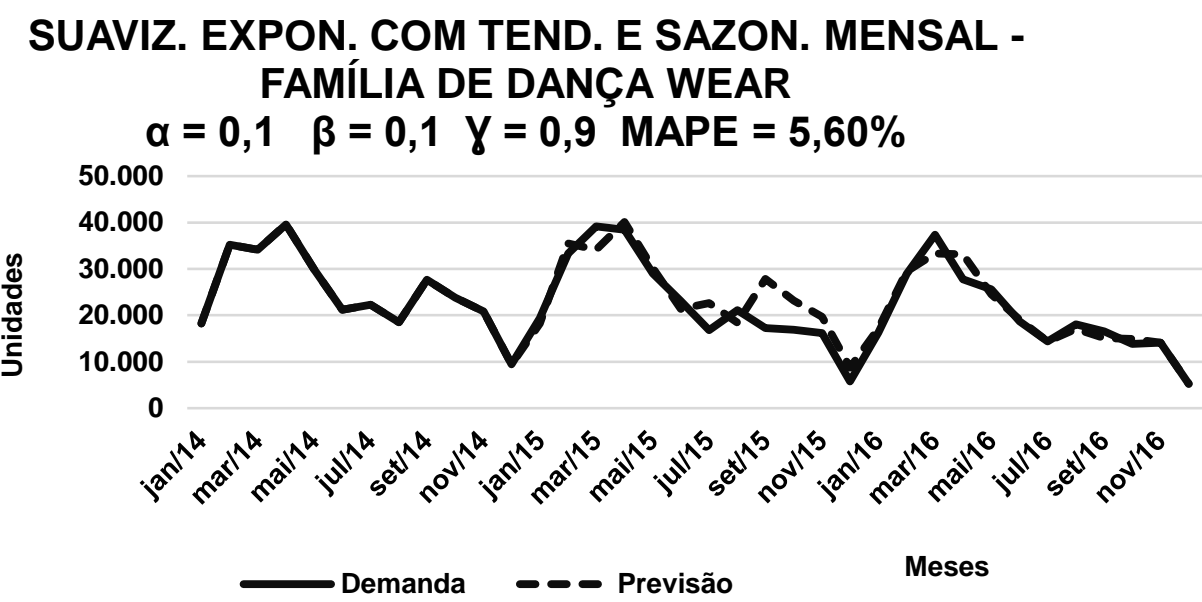

Fonte: Própria autora

Tabela 4 - Resultado dos MAPEs de cada um dos métodos de previsão de demanda testados para a família de artigos fitness

FAMÍLIA DE ARTIGOS FITNESS

\begin{tabular}{lccccc} 
MÉTODOS DE PREVISÃO DE DEMANDA & $\mathbf{n}$ & $\boldsymbol{\alpha}$ & $\boldsymbol{\beta}$ & $\boldsymbol{\gamma}$ & MAPE \\
\hline Média Simples & 7 & & & & $70,00 \%$ \\
Média Móvel & 7 & 1,0 & & & $40,03 \%$ \\
$\begin{array}{l}\text { Suaviz. Expon. } \\
\text { Suaviz. Expon. com Tendência - Método }\end{array}$ & 1,0 & 0,19 & & $33,13 \%$ \\
$\begin{array}{l}\text { de Holt } \\
\begin{array}{l}\text { Suaviz. Expon. com Tend. e Saz. - Método } \\
\text { de Holt-Winters }\end{array}\end{array}$ & 0,3 & 0,00 & 0,2 & $10,20 \%$ \\
\hline
\end{tabular}

Fonte: Própria autora

Por fim, novamente para a família de artigos fitness o melhor método se mostrou ser o de Suavização Exponencial com Tendência e Sazonalidade - Método de Holt-Winters que gerou uma previsão com o menor erro absoluto médio de 10,20\% e pode ser vista na Figura 10.

O método resultou no menor MAPE dentre os testados para a família fitness, utilizando o valor de $\alpha=0,3$, trazendo maior peso as demandas passadas do histórico, enquanto que o beta não foi considerado com a solução encontrada de $\beta=0,0$ que seria usado para suavizar as variações da inclinação da tendência e $\gamma=0,2$ para suavização da sazonalidade.

Após o teste dos métodos na família de meias foram obtidos os seguintes resultados observados na Tabela 5. 
Figura 10 - Demanda X Previsão de demanda mensal obtida com a aplicação do método de Suavização Exponencial com Tendência e Sazonalidade - Método de Holt-Winters na família de artigos fitness

SUAVIZ. EXPON. COM TEND. E SAZON. MENSAL -

FAMÍLIA DE ARTIGOS FITNESS

$\alpha=0,3 \quad \beta=0,0 \quad \gamma=0,2$ MAPE $=10,20 \%$

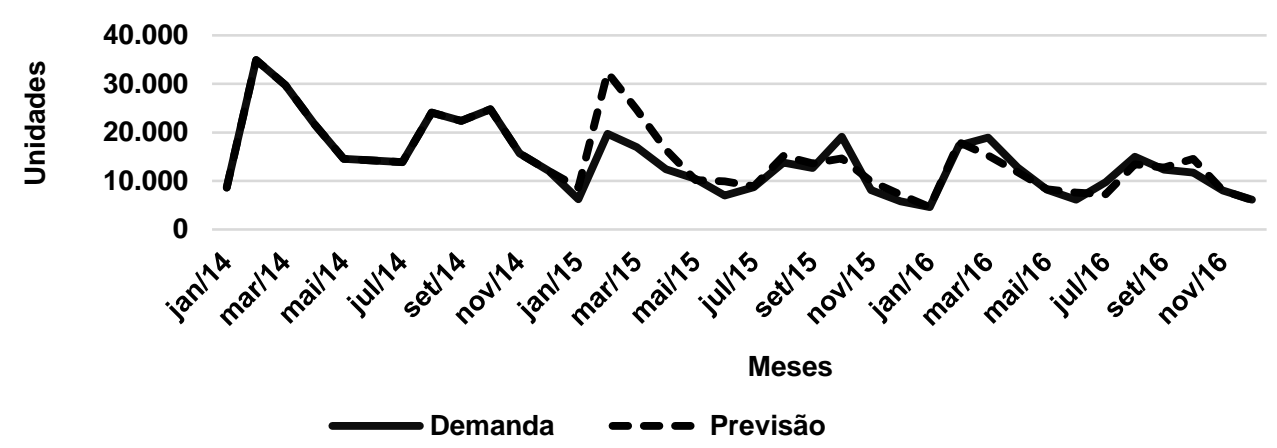

Fonte: Própria autora

Tabela 5 - Resultado dos MAPEs de cada um dos métodos de previsão de demanda testados para a família de meias

\begin{tabular}{|c|c|c|c|c|c|}
\hline \multicolumn{6}{|c|}{ FAMÍLIA DE MEIAS } \\
\hline MÉTODOS DE PREVISÃO DE DEMANDA & $\mathbf{n}$ & $\alpha$ & $\beta$ & $\mathbf{x}$ & MAPE \\
\hline Média Simples & & & & & $32,00 \%$ \\
\hline Média Móvel & 8 & & & & $19,61 \%$ \\
\hline Suaviz. Expon. & & 1,0 & & & $28,42 \%$ \\
\hline $\begin{array}{l}\text { Suaviz. Expon. com Tendência - Método } \\
\text { de Holt }\end{array}$ & & 0,036 & 0,898 & & $17,70 \%$ \\
\hline $\begin{array}{l}\text { Suaviz. Expon. com Tend. e Saz. - Método } \\
\text { de Holt-Winters }\end{array}$ & & 0,300 & 0,000 & 0,9 & $6,00 \%$ \\
\hline
\end{tabular}

Fonte: Própria autora

O método de Média Simples gerou uma previsão com erro absoluto médio de $32,00 \%$, o maior entre os métodos desta família de produtos, acompanhado da Suavização Exponencial com MAPE de 28,42\%, da média móvel que obteve o melhor MAPE sendo de $19,61 \%$, em um intervalo de tempo para cálculo de $n=8$ e a Suavização Exponencial com Tendência teve o menor erro possível de 17,70\%.

Novamente o melhor método de previsão de demanda se mostrou ser o de Suavização Exponencial com Tendência e Sazonalidade - Método de Holt-Winters que gerou uma previsão com o menor erro absoluto médio para a família de meias de 6,00\% que pode ser visto na Figura 11. 
Figura 11 - Demanda X Previsão de demanda mensal obtida com a aplicação do método de Suavização Exponencial com Tendência e Sazonalidade - Método de Holt-Winters na família de meias

\section{SUAVIZ. EXPON. COM TEND. E SAZON. MENSAL - FAMÍLIA DE MEIAS $\alpha=0,3 \quad \beta=0,0 \quad \gamma=0,9$ MAPE $=6,0 \%$}

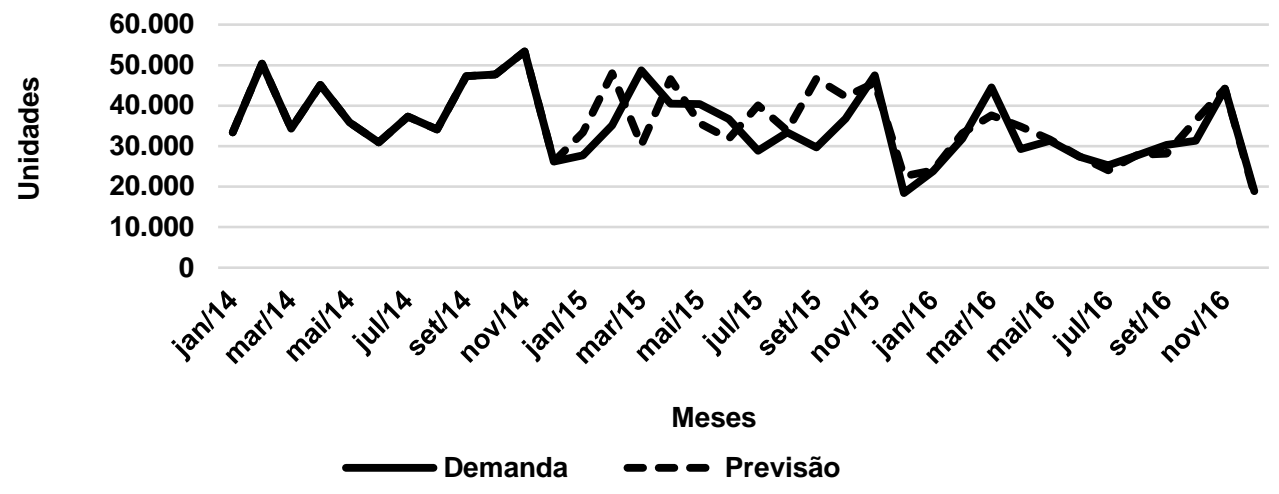

Fonte: Própria autora

O método resultou no menor MAPE dentre os testados para a família de meias utilizando o valor de $\alpha=0,3$, trazendo maior peso as demandas passadas do histórico, enquanto que o beta foi de $\beta=0,0$ que seria usado para suavizar as variações da inclinação da tendência e $\gamma=0,9$ para suavização na sazonalidade.

Após o teste dos métodos, na família de artigos para natação foram obtidos os seguintes resultados observados na Tabela 6 .

Após o cálculo da Média Simples o melhor valor do MAPE encontrado foi de $79,00 \%$, resultando em uma previsão distante da realidade de vendas, enquanto que a Média Móvel gerou uma previsão com erro absoluto percentual médio de 54,37\%, com intervalo de tempo de $n=7$. Já a previsão por meio da utilização da Suavização Exponencial com Tendência - Método de Holt, resultou em um MAPE $=52,60 \%$ e o método de Suavização Exponencial o MAPE foi de 46,80\%.

Tabela 6 - Resultado dos MAPEs de cada um dos métodos de previsão de demanda testados para a família de artigos para a natação

\begin{tabular}{|c|c|c|c|c|c|}
\hline \multicolumn{6}{|c|}{ FAMÍLIA DE ARTIGOS PARA NATAÇÃO } \\
\hline MÉTODOS DE PREVISÃO DE DEMANDA & $\mathbf{N}$ & $\alpha$ & $\beta$ & $y$ & MAPE \\
\hline Média Simples & & & & & $79,00 \%$ \\
\hline Média Móvel & 7 & & & & $54,37 \%$ \\
\hline Suaviz. Expon. & & 1,0 & & & $46,78 \%$ \\
\hline $\begin{array}{l}\text { Suaviz. Expon. com Tendência - Método } \\
\text { de Holt }\end{array}$ & & 0,052 & 0,462 & & $52,60 \%$ \\
\hline $\begin{array}{l}\text { Suaviz. Expon. com Tend. e Saz. - Método } \\
\text { de Holt-Winters }\end{array}$ & & 0,1 & 0,7 & 0,4 & $13,80 \%$ \\
\hline
\end{tabular}

Fonte: Própria autora 
Por fim o método de Suavização Exponencial com Tendência e Sazonalidade - Método de Holt-Winters se mostrou o mais adequado para a previsão de demanda da família de artigos para natação, assim como para todas as famílias anteriores da organização, sendo possível observar na Figura 12 a seguir a previsão para a família de produtos em estudo.

Figura 12 - Demanda X Previsão de demanda mensal obtida com a aplicação do método de Suavização Exponencial com Tendência e Sazonalidade - Método de Holt-Winters na família de artigos para natação

SUAVIZ. EXPON. COM TEND. E SAZON. MENSAL FAMÍLIA DE ARTIGOS PARA NATAÇÃO $\alpha=0,1 \quad \beta=0,7 \quad \gamma=0,4$ MAPE $=13,80 \%$

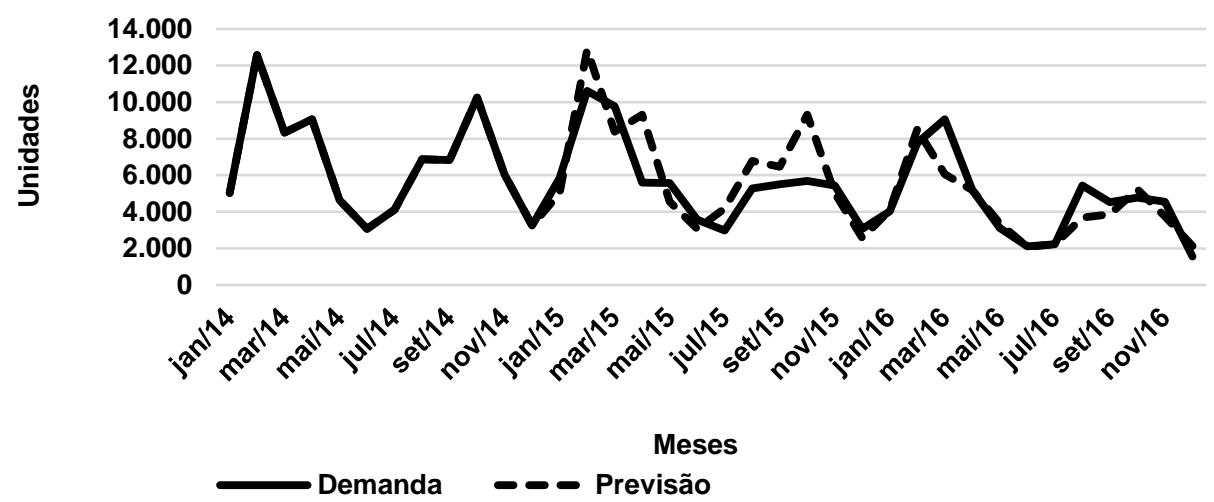

Fonte: Própria autora

O método resultou em um MAPE de 14\% para a previsão, conseguido a partir da combinação de $\alpha=0,1$ suavizando a base histórica, $\beta=0,6$ suavizando a tendência e $\gamma=0,5$ suavizando a sazonalidade que é a principal característica da demanda dessa família de produtos e consequentemente por isso, o método se mostra o mais indicado, projetando uma previsão de demanda mais próxima da demanda.

Após os testes dos cincos métodos de previsão para cada uma das seis famílias de produtos da organização, com horizonte mensal, encontraram-se diferentes níveis de precisão para cada família de produtos, que variaram de acordo com os métodos empregados e por possuírem irregularidades, sazonalidade e tendências diferentes em cada família de produto. 


\section{CONSIDERAÇÕES FINAIS}

Tendo em vista que o segmento de vestuário esportivo vem crescendo atualmente no Brasil, por conta da maior preocupação com a saúde e boa forma por parte da população, as empresas do setor têxtil devem estar preparadas para atenderem tal demanda, através de previsões de demanda que auxiliem na determinação dos recursos necessários para a empresa.

Em geral, com a aplicação do método Wolt-Winters foram projetadas demandas com precisão e dessa forma, com baixo valor de MAPE, exceto para a família de bolsas que possui baixos volumes de vendas e uma demanda esporádica, com pouca previsibilidade, fazendo com que o modelo não se ajustasse da melhor maneira.

Os modelos mais robustos como Holt-Winters costumam apresentar melhores resultados diante dos modelos mais simples como Média Simples, Média Móvel, Suavização Exponencial e Método de Holt, o que foi comprovado no presente trabalho, por conta de sua maior sensibilidade com os coeficientes e por realizar suavizações tanto na tendência quanto na sazonalidade da demanda. No entanto, é o método entre os testados que apresenta maior tempo de execução e por consequência tem a necessidade de recursos computacionais dedicados a execução dos cálculos de previsão de demanda do modelo por um longo período de tempo na busca pela melhor combinação das constantes, fato que deve ser considerado pela organização antes de utilizar tal método.

O segundo melhor método observado na maioria das famílias foi o de Suavização Exponencial com Tendência - Método de Holt, que apresentou maiores erros de previsão, mas se mostrou o mais indicado quando a empresa buscar precisão aliada com agilidade na previsão, exceto para a família de bolsas e de artigos para natação, que tiveram como segundo melhor método o de Suavização Exponencial. Enquanto que o método que apresentou os piores índices de previsão em todas as famílias de produto se mostrou ser o de Média simples, por ser o menos robusto e com menor sensibilidade as características da demanda.

Por fim, a realização de previsões de demanda a partir dos métodos utilizados pode contribuir com as decisões que envolvem o planejamento da produção e gerenciamento de estoques e essa seria ainda mais eficaz caso a empresa, alia-se o 
modelo quantitativo com métodos qualitativos, para validar as previsões e buscar estratégias, por meio do acompanhamento do mercado e suas tendências. Já que se acredita que o presente trabalho por meio da aplicação dos métodos de previsão de demanda possa auxiliar na melhor disponibilidade de recursos, gerenciamento de estoque, garantia de serviço ao consumidor e consequentemente gerar ganhos financeiros a organização.

\section{REFERÊNCIAS}

ASSOCIAÇÃO BRASILEIRA DE ACADEMIAS. Relatório Global IHRSA: Fitness cresce no mundo e Brasil ainda sofre com a crise econômica. Revista ACAD Brasil. 2017. Disponível em: http://download.ihrsa.org/brasil/MATERIA DE CAPA DIRETO.pdf.

ALBERTIN, M. R.; PONTES, H. L. J. Administração da produção e operações. Curitiba: InterSaberes, 2016.

BALLOU, R. H. Gerenciamento da cadeia de suprimentos/logística empresarial.

Tradução de Raul Rubenich. 5. ed. Porto Alegre: Bookman, 2006.

CHASE, R. B; JACOBS, F. R.; AQUILANO, N. J. Administração da produção e operações para vantagens competitivas. Tradução de Cláudia Freire, Lucas Marcelo Ferretti Yassumura e Monica Rosali Rosemberg.11. ed. São Paulo: McGraw-Hill, 2006.

CHOPRA, S. MEINDL, P. Gestão da cadeia de suprimentos: estratégia, planejamento e operação. Tradução de Sérgio Nascimento. 6. ed. São Paulo: Pearson Prentice Hall, 2016.

CORREAA, H. L.; GIANESI, I. G. N.; CAON, M. Planejamento, programação e controle da produção: MRP II/ERP: conceitos, uso e implantação: base para SAP, Oracle Applications e outros softwares integrados de gestão. 5. ed. São Paulo: Atlas, 2013.

DA CUNHA, L. B. As roupas esportivas em Revista na cidade de Belo Horizonte (1929 1950). 2011. Disponível em: http://repositorio.unicamp.br/handle/REPOSIP/275049.

DE SOUZA, A. A. A importância do planejamento, programação e controle da produção no mercado atual como ferramenta estratégica empresarial. 2012. Disponível em : http://www.avm.edu.br/docpdf/monografias publicadas/K219306.pdf.

FENERICH, F.C. Administração dos sistemas de operações. Curitiba: InterSaberes, 2016.

GONÇALVES, P. C. Logística e cadeia de suprimentos: o essencial. Barueri: Manole, 2013.

KRAJEWSKI, L.; RITZMAN, L.; MALHOTRA, M. Administração de produção e operações. 8. ed. São Paulo: Pearson Prentice Hall, 2009.

LEMOS, F. de O. Metodologia para seleção de método de previsão de demanda. 2006.

Disponível em: http://www.lume.ufrgs.br/handle/10183/5949. 
MARTINS, R. A. Abordagens quantitativa e qualitativa. In: MIGUEL, C. P. M. Metodologia de Pesquisa em Engenharia de Produção. 2. ed. Rio de Janeiro: Elsevier: ABEPRO, 2012.

MESQUITA, M. A. Previsão de demanda. In: LUSTOSA, Leonardo J. Planejamento e controle da produção. São Paulo: Elsevier, 2008.

MOREIRA, D. A. Administração da produção e operações. 2. ed. São Paulo: Cengage Learning, 2013.

PARANHOS FILHO, M. Gestão da produção industrial. Curitiba: InterSaberes, 2012.

RITZMAN, L.P.; KRAJEWSKI, L. J. Administração da produção e operações. Tradução de Roberto Galman. São Paulo: Pearson Prentice Hall, 2004.

SEBRAE. Prática de esportes aumenta ritmo do comércio de calçados e produtos esportivos. 2014. Disponível em: http://www.sebraemercados.com.br/pratica-de-esportesaumenta-ritmo-do-comercio-de-calcados-e-produtos-esportivos/.

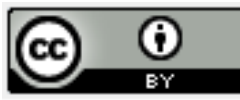

Artigo recebido em: 11/08/2018 e aceito para publicação em: 03/03/2020

DOI: http://dx.doi.org/10.14488/1676-1901.v20i1.3343 